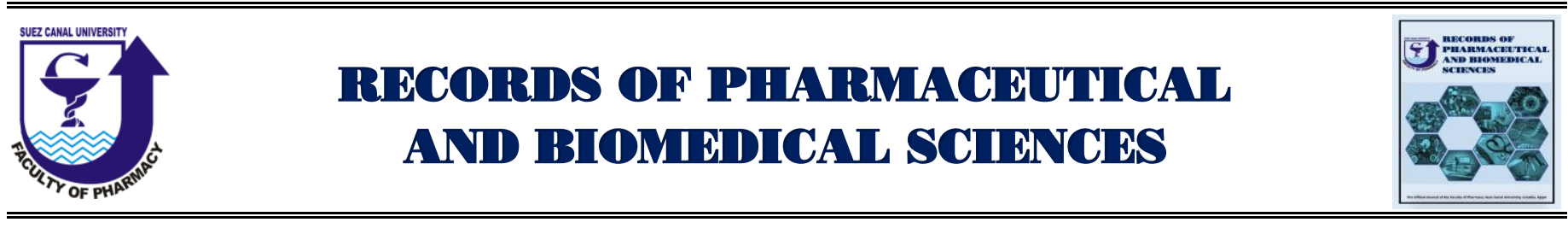

\title{
Anxiolytic-like effect of Pregabalin in mice tested in the dark/light box and the elevated plus maze test: effect on cannabinoid CB1 receptors
}

\author{
Faten A. AlAbkal ${ }^{\text {** }}$, Sawsan A. Zaitone ${ }^{\text {b,c }}$, Yasser M. Moustafa ${ }^{b}$
}

${ }^{a}$ Ministry of Health, Kuwait City, Al-Kuwait

${ }^{\mathrm{b}}$ Department of Pharmacology and Toxicology, Faculty of Pharmacy, Suez Canal University, Ismailia 41522, Egypt

${ }^{\mathrm{c}}$ Department of Pharmacology and Toxicology, Faculty of Pharmacy, University of Tabuk, Kingdom of Saudi Arabia

Received on: 23.12 .2016

Revised on: $\quad 17.01 .2017$

Accepted on: 19.01.2017

\section{Keywords}

$\mathrm{A}_{2}$ receptors

Anxiety

Dark-light box

Elevated plus maze

Pregabalin

\begin{abstract}
Pharmacotherapy of generalized anxiety disorders has been depended on benzodiazepines for many decades. However, the use of these compounds is restricted because of their adverse effects. Pregabalin is an anticonvulsant indicated as adjunctive therapy for treating adults' partial seizures. It has shown some efficacy in randomized, placebo-controlled clinical trials aimed to treat generalized anxiety disorder. Mechanism of pharmacologic activity of Pregabalin was extensively studied and it was proven to acquire high-affinity binding to $\alpha 2 \delta$. The current study employed the dark/light box and the elevated plus maze. Male albino mice were allocated into groups: group i: mice received distilled water (16 ml/kg, p.o.), group ii: mice received diazepam (1 mg/kg, p.o.), group iii-iv: mice received a dose of Pregabalin ( 25 or $50 \mathrm{mg} / \mathrm{kg}$, p.o.), group v: mice treated with rimonabant $(1 \mathrm{mg} / \mathrm{kg}$, i.p.) $30 \mathrm{~min}$ before a dose of Pregabalin (50 $\mathrm{mg} / \mathrm{kg}$ ), group vi: mice received rimonabant $(1 \mathrm{mg} / \mathrm{kg}$, i.p.) $30 \mathrm{~min}$ before a dose of distilled water (16 ml/kg, p.o.). Results indicated that Pregabalin $(50 \mathrm{mg} / \mathrm{kg}$ ) showed anxiolytic effect in the two paradigms, the dark/light transition box and the mouse elevated plus maze. Pretreatment with rimonabant diminished most of the anxiolytic effect of Pregabalin $(50 \mathrm{mg} / \mathrm{kg})$ as indicated by shorter time spent in white are in the dark/light box and shorter open arm time (\%) compared to mice received Pregabalin.
\end{abstract}

*Corresponding author

Business Tel: +20-0111-1690365

Fax: +20-64-3230741

E-mail: abchoola@gmail.com 


\section{Introduction}

Anxiety consists of a diversity of subjective sensations reflecting responses to events or stimuli (Etkin, 2009). Anxiety is manifested as a number of physical and mental symptoms without logic cause. Mental symptoms of anxiety include discomfort and apprehension. Anxiety may appear in healthy individuals when show unspecific frightening cues. There are symptomatic responses to anxiogenic stimuli including tachycardia, dizziness, muscle tension, nausea and chest or abdominal pain.

The symptoms of generalized anxiety disorder (GAD) are physical and psychological. For the psychological part, patients with GAD experiences anxiety and hypervigilance, which refer to the propensity to a mental scan for the environment for anticipating stress factors. Furthermore, people with GAD may startle easily and feel irritable and impatient. Thus, the patient may never be free of worries, that is, negative anticipation of the "next bad thing (fear from fear)."

Pharmacotherapy of GAD has dominated by benzodiazepines for many years. However, use of benzodiazepines is limited nowadays because of the adverse effects which include tolerance, sedation, physical dependence, interaction with other CNS depressants and the development of abstinence syndromes which hinder the chronic use (Woods et al., 1992). Therefore, research should be dedicated for discovering novel anxiolytics with enhanced adverse-effect profile.

The light/dark transition paradigm depends on that bright illuminated areas are aversive to rodents and on spontaneous exploring of rodents in response to a new environment in which light which act as a mild stressor. The test apparatus is composed of a dark and safe area and an open illuminated aversive area. Originally, the test was generated for application in male mice. However, the age, strain or weight is critical for this. The magnitude of modifying the exploratory activity relies on the baseline level in the control group of mice. Changes in the type and severity of external stressors contribute to the variability in findings reported by different laboratories.

Further, the light/dark transition paradigm is a test for prediction of anxiolytic-like activity in mice. The recorded transition has been dedicated as an index of activity or exploration because of habituation and the time spent in each part (light or dark areas) are considered as appropriate reflection for aversion. Benzodiazepines and newer anxiolytic-like compounds can be screened by the aid of this test. It is advantageous with regards of quickness and easiness in application, without required prior training of animals; thus animals should be naïve to this test.

Pregabalin $[S-(+)-3$-isobutylGABA] is an adjunctive anticonvulsant therapy partial seizures in adult humans. Efficacy was reported in randomized, placebo-controlled clinical trials for treating GAD (Feltner et al., 2003; Rickels et al., 2005; Montgomery et al., 2005) and has also shown efficacy in clinical trials for neuropathic pain and fibromyalgia related to postherpetic neuralgia and diabetic neuropathy, respectively (Dworkin et al., 2010; Arnold et al., 2010). The pharmacologic 
mechanism of Pregabalin was previously examined in rodents. Studies using series of compounds with structures related to Pregabalin propose that highaffinity binding to $\alpha 2 \delta$ are perfectly predicting anxiolytic action in the Vogel conflict model, which is one of the most predictive assays for screening pharmacological agents with anxiolytic-like properties (Vogel et al., 1971; Belliotti et al., 2005). It was previously mentioned that Pregabalin possesses anxiolytic-like action in the mouse elevated plus maze, one animal model of post-traumatic stress disorder and Geller conflict test (Zohar et al., 2008).

Many receptors are reported to be involved in pain modulation like: cannabinoid type 1 receptors $\left(\mathrm{CB}_{1}\right)$, 5-HT 3 and opioid receptor (Manzanares et al., 2006; Faerber et al., 2007; Mellar and Gavril, 2009). CB 1 receptors are known to be located in both peripheral and central neurons. The distribution pattern of $\mathrm{CB}_{1}$ receptors is mainly in basal ganglia, hippocampus, cortex and cerebellum within the CNS (Compton et al., 1990). $\mathrm{CB}_{1}$ receptors are also located in the superficial layers of spinal dorsal horn beside other locations like the the peripheral terminals of primary afferent neurons and within the pain descending pathway (Svizenska et al., 2008). Some CB 1 receptors are located in peripheral and central nerve terminals. When they are activated, they modulate the release of inhibitory and excitatory neurotransmitters. It remains for elucidation whether the interaction of Pregabalin with voltage activated $\mathrm{Ca}^{++}$channels is sufficient to explain the broad clinical spectrum (Sills, 2006). Little is known about the possible involvement of $\mathrm{CB}_{1}$ activation in the anxiolytic effect of Pregabalin, the present work aimed to determine whether the anxiolytic action of Pregabalin in two behavioral paradigms for mice involves activation of $\mathrm{CB}_{1}$ receptors.

\section{Materials and methods}

\subsection{Animals}

All experimental protocols were approved by the Research Ethics Committee at the Faculty of Pharmacy, Suez Canal University. Male Swiss mice, with body weights range 18-28 g, were purchased from the Modern Veterinary Office for Laboratory Animals (Cairo, Egypt). Naïve mice were used in drug treatment and experimentation groups and allowed to acclimatize for one week before rolling them into the experiment. Mice were housed in polyethylene cages under controlled laboratory conditions $\left(26 \pm 2{ }^{\circ} \mathrm{C}\right.$ temperature and normal dark/light cycle). Food and water were available $a d$ libitum during the acclimatization period. All experiments were conducted between 12:00 and 18:00 $\mathrm{h}$ to eliminate circadian influence on animal behavior.

\subsection{Pharmacological agents}

Pregabalin was purchased from Pfizer manufacturing Deutschland GmbH (Freiburg, Germany) and dissolved in distilled water. Diazepam was obtained in form of Valpam ampoules (Amoun Pharmaceutical Company, Cairo, Egypt). Rimonabant (Sanofi Aventis, Paris, France) was dissolved in DMSO.

\subsection{Experimental design}

Mice were randomly divided into two experiments. Mice were randomly allocated for the EPM test and classified into different groups $(n=6$ mice per group).

\subsubsection{Experiment I}


Mice were classified as vehicle (distilled water) group, diazepam group, Pregabalin (25 or $50 \mathrm{mg} / \mathrm{kg}$ ) treated groups, diazepam $(1 \mathrm{mg} / \mathrm{kg})$ group. The high dose of Pregabalin $(50 \mathrm{mg} / \mathrm{kg})$ was effective and provided anxiolytic effect. However, mice treated with the high dose $(100 \mathrm{mg} / \mathrm{kg})$ showed some sedation and decreased motor activity; therefore, the dose $50 \mathrm{mg} / \mathrm{kg}$ was used for testing with the activity of Pregabalin with different receptor agonist/antagonists. For further elucidation of the mechanism of action, Pregabalin was tested in combination with some receptor agonist/antagonists as follows:

\subsubsection{Experiment II}

Mice were assigned in the following groups as: Rimonabant (1 mg/kg, i.p.) + Pregabalin (50 mg/kg) group. In addition, control groups were assigned as following to help eliminate any effect for the drug vehicles. However, data taken from these groups were not shown in illustrations. Double vehicle group $(\mathrm{DMSO}+$ distilled water) and DMSO+ Pregabalin (50 $\mathrm{mg} / \mathrm{kg}$ ) group were used for excluding any pharmacological activity of the solvents.

For determination of the per se effect of each receptor agonist/antagonist the following group was assigned as, rimonabant+ distilled water in the same aforementioned doses. In another set of the experiment, mice were assigned for the light-dark box. In general, Pregabalin (or distilled water) was administered by oral gavage however; rimonabant was given by intraperitoneal injection.

\subsection{Justification of doses}

Doses of Pregabalin were selected based on previous studies (Eutamene et al., 2000) used Pregabalin (1, 3, 10 and $30 \mathrm{mg} / \mathrm{kg}$ p.o.) for antiallodynic effect in mice with lipo-induced rectal hypersensitivity in rats (Lauria-Horner and Pohl, 2003) reported that Pregabalin [ED50] $=87 \mathrm{mg} / \mathrm{kg}$ administered orally in blocking maximal electroshock seizures induced in mice. In another study, mice were given of Pregabalin $(10,30$ and $100 \mathrm{mg} / \mathrm{kg})$ through the oral route or vehicle and challenged with pentylenetetrazole at the previously mentioned doses $\left(\mathrm{ED}_{50}=31 \mathrm{mg} / \mathrm{kg}\right.$, p.o. $)$ against clonic seizures from pentylenetetrazole in mice (Vartanian et al., 2006).

Doses of the receptor antagonists were selected relying on data obtained from the literature plus confirmation in our hands in our laboratory. Selection of doses was adjusted towards the lowest reported to provide adequate blocking to the receptor. In case of single drug administration, all drugs were given 30 min before testing in the elevated plus maze (EPM) or the light/dark transition box, whereas, in combination groups, rimonabant (or DMSO) was given $30 \mathrm{~min}$ before the second one and, mice were tested in the EPM after $30 \mathrm{~min}$.

\subsection{Behavioral assessment}

Mice were utilized for each of the following experiments; each experiment was done separately.

\subsubsection{Dark-light transition box}

The test relies on that illuminated bright areas are aversive to rodents and on the exploration done by mice that occurs spontaneously in reaction to mild stressful conditions in novel environment and in light compartments (Crawley and Goodwin, 1980). A conflict is created if the animal is subjected to a non- 
familiar environment. This conflict develops between the natural tendency of mice towards exploration of new environments and that mice initially tend to avoid the unfamiliar environment, which is called neophobia. Further, the exploratory activity of rodents expresses the combination of these behaviors in a novel situation.

Therefore, the increments in behavior in the white area that induced after drug administration of a transition box composed of two compartments can be detected. Any increase in transition without a concomitant greater spontaneous locomotion is a reflection to the anxiolytic effect. The widely-agreed fact that this effect is only observed in certain mice strains and after definite drug categories. This model is unique among other known paradigms for testing anxiety which are not equal in terms of the elicited or induced emotional state (File, 1992; De Vry et al., 1993).

The test depends on the initial rodent paradigm created by Crawley and Goodwin (1980), scientists usually use it with many reported modifications to the structure. Thus, the light/dark test is useful to predict either the anxiolytic-like or anxiogenic-like activity of drugs. It acquires some unique properties like easy to apply and quick, without the necessary pre-training for animals, there is no food or water deprivation and that natural stimulus is employed.

The process of transition has been utilized as an index of exploratory activity because of habituation while time spent in each of the two compartments reflects aversion (Belzung et al., 1987). Indeed, it is superior to measure to the percent of time spent and the movements/exploratory behavior in each compartment (Hascoet and Bourin, 1998). Some of the known animal models for recording behavioral changes are based on spontaneous behavior or ethological measures (like the light/dark test) may be more sensitive to the behavioral responses than conditioned paradigms (Lister, 1990; Griebel, 1996).

\subsubsection{Elevated plus maze}

The maze is a commonly utilized test for unconditioned anxiety, first developed by File and collaberators (Pellow et al., 1985). This apparatus is composed of an elevated, runway in a plus-sign shape with two arms opposing each other, two arms are closed by walls and the other two arms are designed in an open fashion. Every mouse is usually placed at the middle of the four arms (central square of maze) facing one of the closed arms, at the point where the four arms meet each other. The test depends on that elevated areas are aversive and rodents tend to avoid it.

Following the hypothesis of avoidance behavior in rodents, avoidance behavior for the two open arms is usually interpreted by anxiolytic agents (Rodgers et al., 1997). An anxiolytic agent raises the ratio of activity in open arms of the maze (the increment in the $\%$ of time spent in open arms, in the percentage of entries into the open arms and number of head dips within the open sides). However, amelioration of total arm entries or in the number of entries into closed arms refers to non-specific effects for the drug on the motor function (Carobrez and Bertoglio, 2005). The reliability and sensitivity of this test increases when using more detailed approaches to analyze rodent behavior on the EPM, such as determining the risk assessment behavior (Weiss et al., 1998). Patients with anxiety can also display fear from open spaces and high places, and may even display thigmotaxis 
and risk assessment under these conditions and this point to some degree of homology (Rodgers et al., 1997).

The testing paradigm was designed as previously introduced by Lister (1987) and composed of four arms: two open arms with dimensions $30 \times 5 \times 0.25 \mathrm{~cm}$ and another two closed arms with dimensions $30 \times 5 \times 15 \mathrm{~cm}$. The four arms are extending from a central platform $(5 \times 5 \mathrm{~cm})$ between them. The apparatus is traditionally composed of wood painted in dark color and the arms are elevated $45 \mathrm{~cm}$ above the floor level.

Mice were allowed to habituate undisturbed at the testing room for $2 \mathrm{~h}$ or more prior to the start of the experiment. Each mouse was taken individually from the home cage and moved to the testing wooden apparatus after drug administration for $30 \mathrm{~min}$. Each moue was then individually introduced to the middle platform while its face at the direction of any of the open arms to encourage it to move. Experimentation lasts for 3-5 min and vedio recording was done employing a digital camera. Importantly, cleaning for the maze was done by $10 \%$ ethyl alcohol solution between each two mice, this process was followed by drying with a dry cotton piece. Later on, the vedios were observed blindly.

The parameters measured in this test contain ethological and spatiotemporal measurements (Holmes and Rodgers, 1998). First, conventional measurements include the frequency of entries to the open and closed arms (arm entry means = all four paws come into a specified arm) and the time spent in the open and closed arms. Second, exploration of the open arms is usually used as an index for anxiety. Open-arm exploration was characterized by: \%OAT as a percent of the total session time. Increases in both \%OAT has been shown to be an index of lowered anxiety behavior. The total number of head dips (an exploratory action for the head and shoulders toward the floor under the apparatus) is an important ethological parameter. If a mouse fell off the arms, it was excluded from the group data.

\subsection{Statistical Analysis and data manipulation}

Data were expressed as mean \pm S.E.M. Data analysis was done by applying one-way analysis of variance followed by Bonferroni's post-hoc test. Tests were done by employing the Statistical Package for Social Sciences. Differences were considered significant if $\mathrm{P}<0.05$.

\section{Results}

Data documented that treatment with diazepam (1 $\mathrm{mg} / \mathrm{kg}$ ) or Pregabalin $(50 \mathrm{mg} / \mathrm{kg})$ in mice produced significant changes in anxiety behavior in 2 well documented models of anxiety.

First, results of the dark/light transition box revealed that treatment with diazepam $(1 \mathrm{mg} / \mathrm{kg})$ or Pregabalin $(50 \mathrm{mg} / \mathrm{kg})$ significantly increased time spent in light box (Figure 1) and number of entries into the light compartment (Figure 2) compared to the control group received distilled water. Per se treatment with rimonabant $(1 \mathrm{mg} / \mathrm{kg})$ did not produce significant changes in the measured parameters in comparison to control (distilled water) mice.

However, pretreatment with rimonabant $(1 \mathrm{mg} / \mathrm{kg})$ before Pregabalin $(50 \mathrm{mg} / \mathrm{kg}$ ) decreased time spent by 


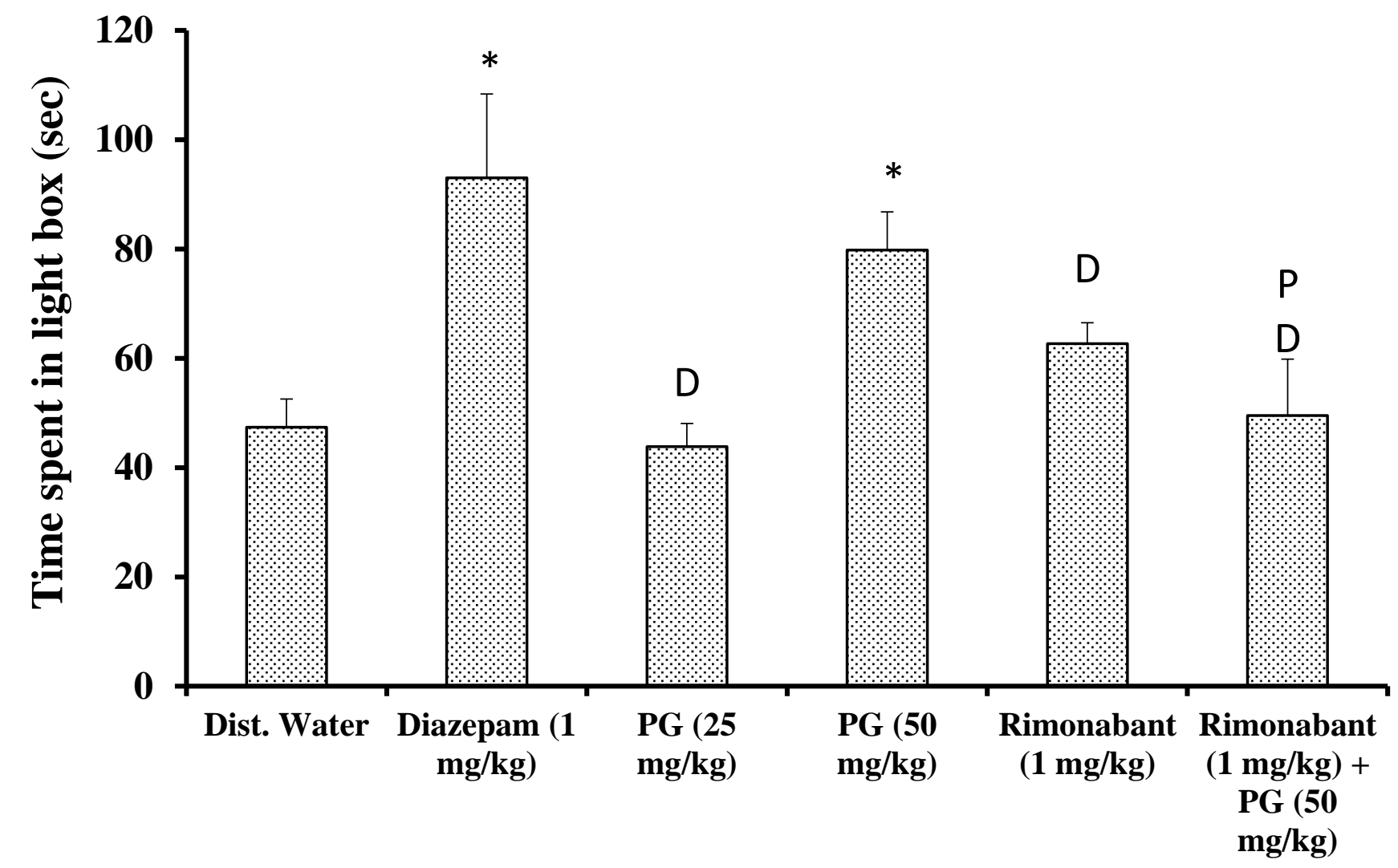

Figure 1. Effect of pregabalin ( 25 and $50 \mathrm{mg} / \mathrm{kg}$ ) versus diazepam on time spent in the light area of the mouse dark/light transition box. After drug administration by $30 \mathrm{~min}$, every mouse was introduced individually in the transition box at the starting point in the liht area and vedio recorded for a period of 3 minutes. Mice in the last group received rimonabnat $(1 \mathrm{mg} / \mathrm{kg})$ prior to pregabalin. Data are mean $\pm \mathrm{SEM}$ and were analyzed using one-way ANOVA. Post-hoc analysis was performed to detect difference between individual groups at $\mathbf{P}<0.05$. * Significantly different from Dist. Water group, ${ }^{\mathrm{D}}$ Significantly different from diazepam group, ${ }^{\mathbf{P}}$ Significantly different from pregabalin $(50 \mathrm{mg} / \mathrm{kg})$ group.

mice in the light box compared to Pregabalin (50 $\mathrm{mg} / \mathrm{kg}$ ) group which refers to diminishing the anxiolytic activity. Differently, this pretreatment did not modify the number of entries to the light compartment (Figure 3).

Moving to the elevated plus maze results, treatment with Pregabalin $(50 \mathrm{mg} / \mathrm{kg})$ or diazepam $(1 \mathrm{mg} / \mathrm{kg})$ in mice significantly raised the open arm time (\%) and number of head dips compared to control group. Similar to the dark/light transition box, per se treatment with rimonabant $(1 \mathrm{mg} / \mathrm{kg})$ did not result in changes in the two measured parameters in comparison to the control group (Figure 4).

The preadministration of rimonabant before Pregabalin $(50 \mathrm{mg} / \mathrm{kg})$ gave rise to changes in the measured parameters; open arm time (\%) and number of head dips. In general, results indicate that the cannabinoid receptor antagonist, rimonabant, antagonized most of the anxiolytic effects of Pregabalin in mice.

\section{Discussion}

One difficulty during testing anxiety disorders in experimental studies is the lack of concrete 


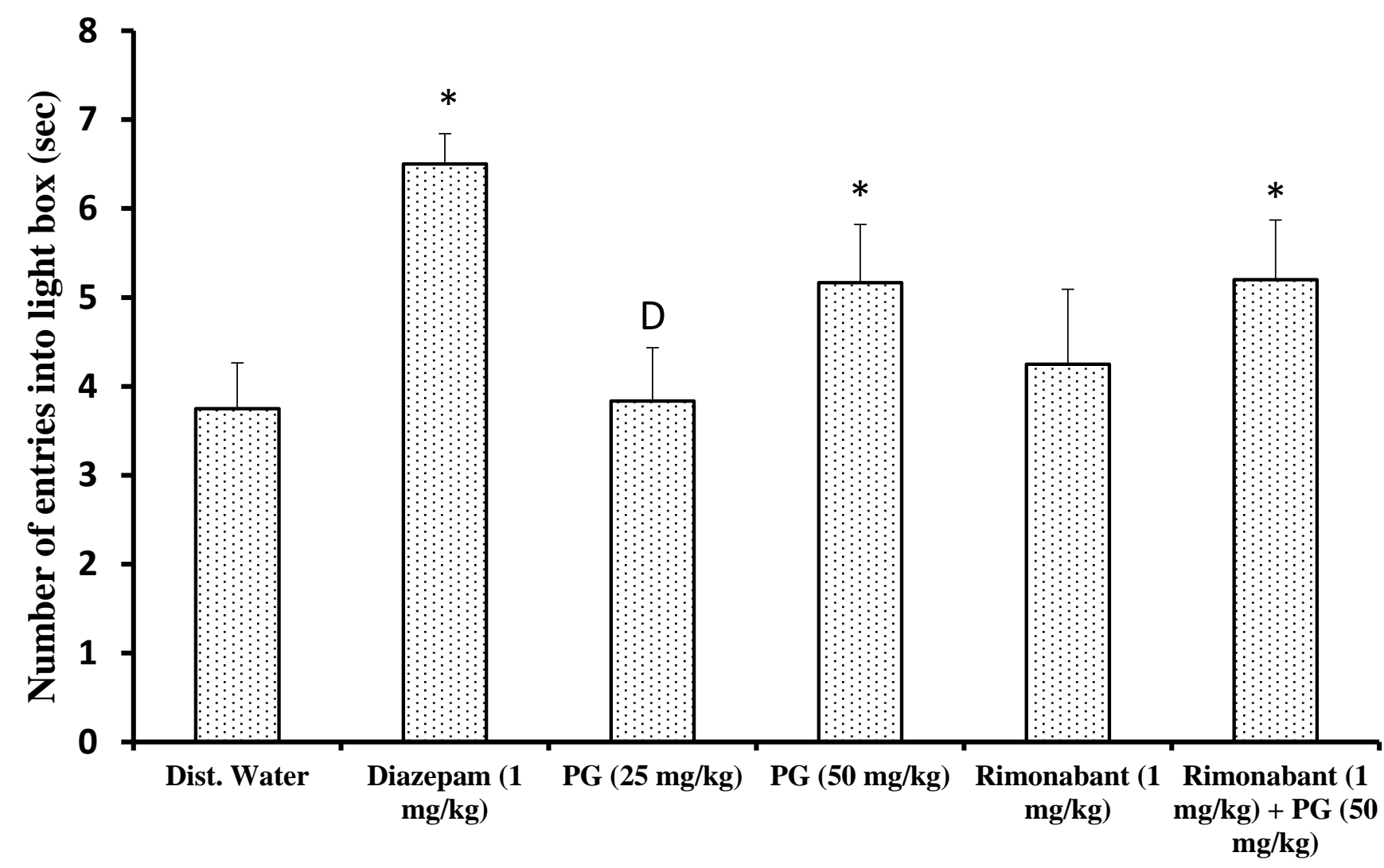

Figure 2. Effect of pregabalin ( 25 and $50 \mathrm{mg} / \mathrm{kg}$ ) versus diazepam on the number of entries to the light area of the mouse dark/light transition box. After drug administration by $30 \mathrm{~min}$, every mouse was introduced individually in the transition box at the starting point in the liht area and vedio recorded for a period of 3 minutes. Mice in the last group received rimonabnat $(1 \mathrm{mg} / \mathrm{kg})$ prior to pregabalin. Data are mean \pm SEM and were analyzed using one-way ANOVA. Post-hoc analysis was performed to detect difference between individual groups at $\mathbf{P}<\mathbf{0 . 0 5}$. * Significantly different from Dist. Water group, ${ }^{D}$ Significantly different from diazepam group, ${ }^{\mathrm{P}}$ Significantly different from pregabalin $(50 \mathrm{mg} / \mathrm{kg})$ group.

parameters reflecting per se anxiety disorder. Many testing apparatuses have been created for the exploration of behavioural parameters related to anxiety in rodents. Rodents are important as they are the most widely utilized animals in experimental research. Furthermore, rodents are useful in behavioral phenotyping of drugs that modify distinct aspects of anxiety. Importantly, behavioural manifestations represent a combination of behavioural aspects controlled by genetic and environmental factors. Findings coming from a behavioral test may be determined by testing conditions and the testing procedures. Hence, it is necessary for careful defining of these factors while undergoing a test for anxiety (Ohl, 2005).

Similar to animal models of other human diseases, quality of any animal model of is primarily determined by three validating properties: First, face validity, which describes how closely the animal model can mimic the principle symptoms of the disease in human, second predictive validity which detects the success of the animal model for a 


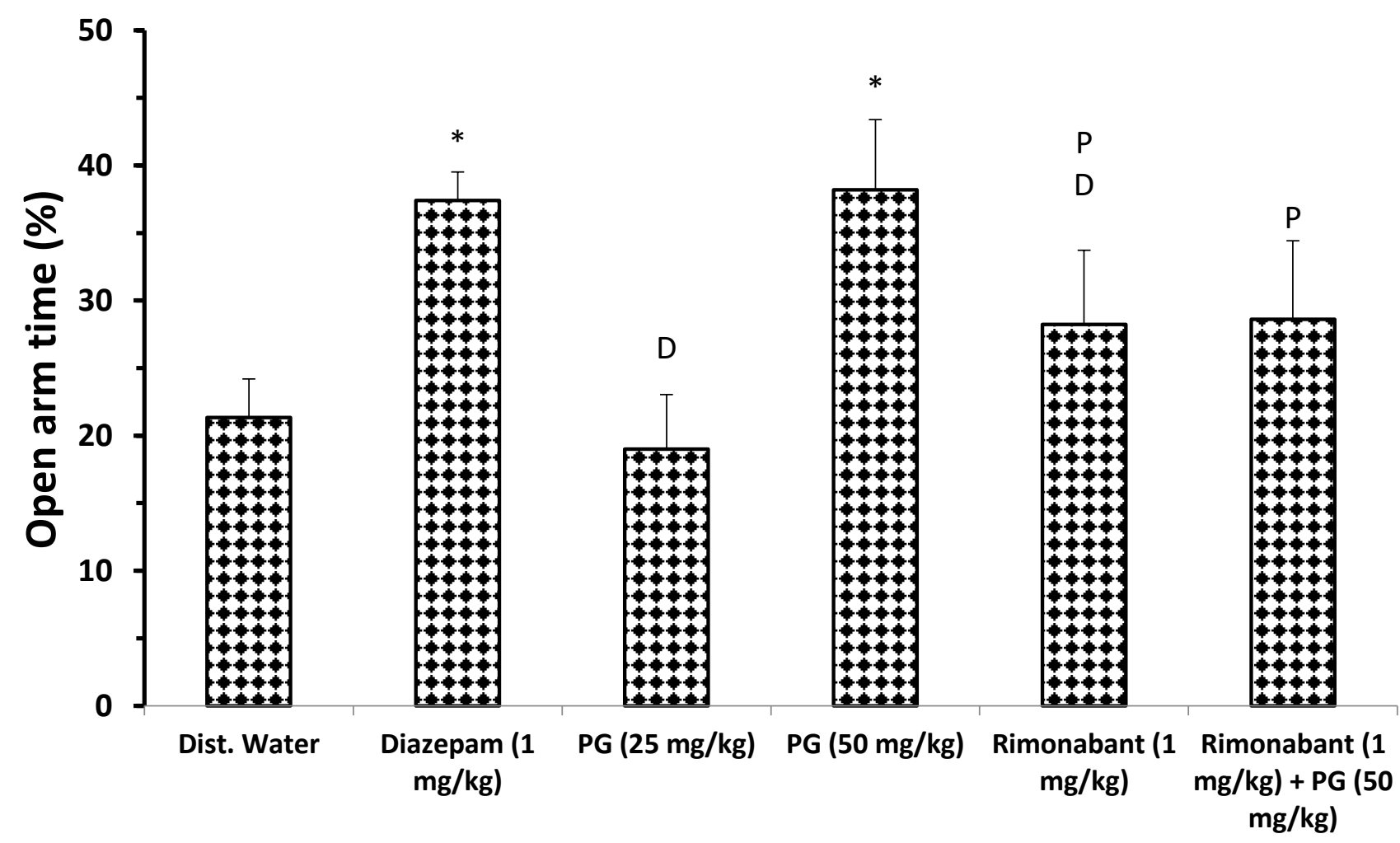

Figure 3. Effect of pregabalin ( 25 and $50 \mathrm{mg} / \mathrm{kg}$ ) versus diazepam on time spent in the open arm \%, in the mouse elevated plus maze. After drug administration by $30 \mathrm{~min}$, every mouse was introduced individually at the center of the maze facing the open arms and vedio recorded for a period of 3 minutes. Mice in the last group received rimonabnat $(1 \mathrm{mg} / \mathrm{kg})$ prior to pregabalin. Data are mean $\pm S E M$ and were analyzed using one-way ANOVA. Post-hoc analysis was performed to detect difference between individual groups at $\mathbf{P}<0.05$. * Significantly different from Dist. Water group, ${ }^{\mathrm{D}}$ Significantly different from diazepam group, ${ }^{\mathrm{P}}$ Significantly different from pregabalin $(50 \mathrm{mg} / \mathrm{kg})$ group.

pharmacological treatment, which is therapeutically effective in humans; and third, construct validity which refers to the analogous nature of molecular event in the model and the human disease (Guo, 2008).

The results showed that Pregabalin possessed anxiolytic-like activity in elevated plus maze and mouse light/dark tests. These results came convenient with those obtained previously (Field et al., 2001; Zohar et al., 2008). These authors discovered that Pregabalin exerted anxiolytic activity in rat conflict, elevated plus maze and coustic startile response tests. Furthermore, Pregabalin exhibits anxiolytic activity in previous clinical studies (Frampton and Foster, 2006; Pande et al., 2004).

The mechanism of the anxiolytic activity of Pregabalin is not fully determined and little data are available about the role of $\mathrm{CB}_{1}$ receptors in the anxiolytic mechanism of Pregabalin. However, there are many evidences about the role of CB1 receptors in anxiety. In the CNS, adenosine acts primarily as an inhibitory neuromodulator, exhibits many behavioral responses (Barraco, 1991).

In light/dark test for the first time to demonstrate the anxiolytic effect of Pregabalin in mice and the role of cannabinoid receptors. However, the pretreatment 


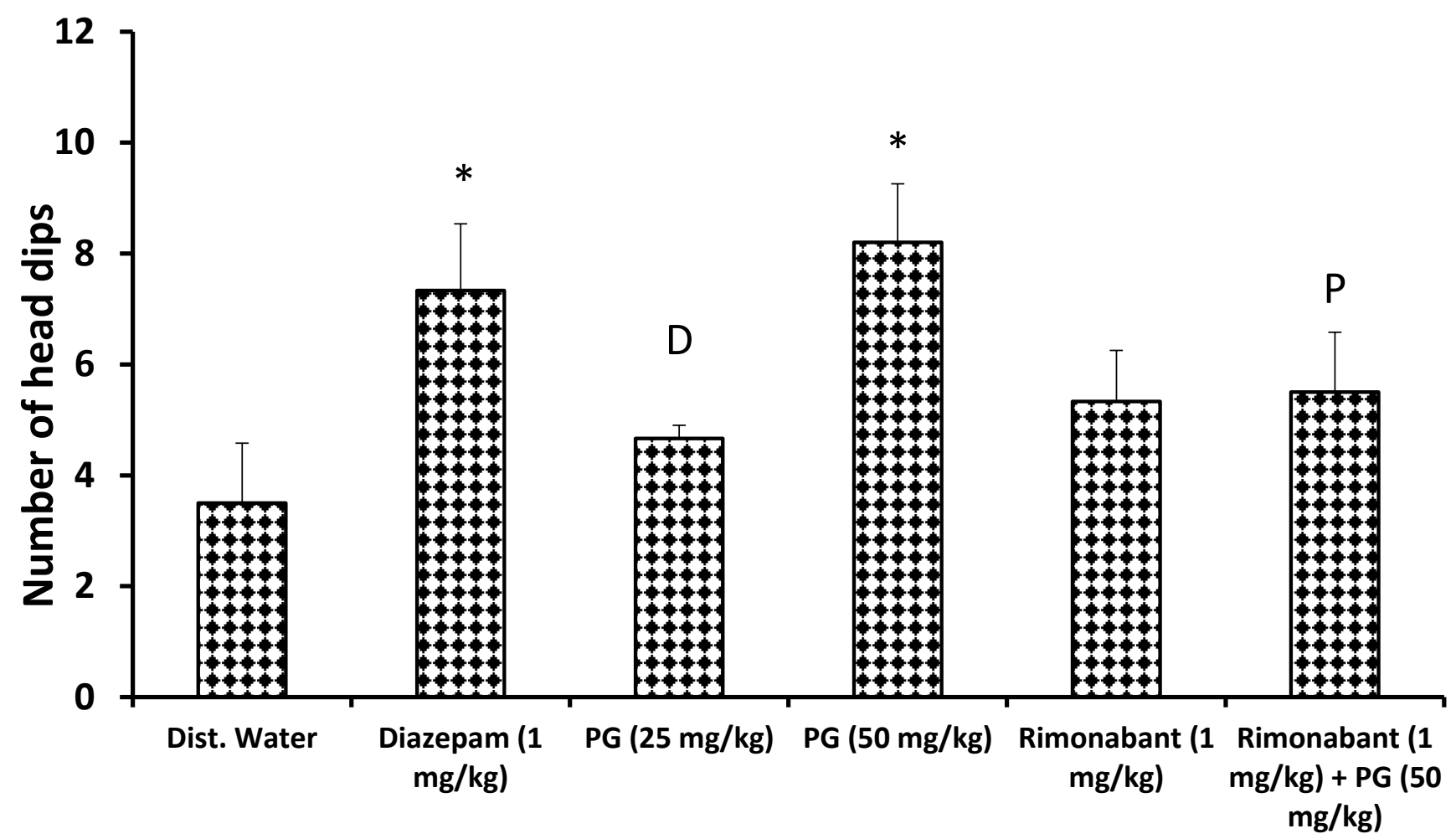

Figure 4. Effect of pregabalin ( 25 and $50 \mathrm{mg} / \mathrm{kg}$ ) versus diazepam on number of head dips in the mouse elevated plus maze. After drug administration by $30 \mathrm{~min}$, every mouse was introduced individually at the center of the maze facing the open arms and vedio recorded for a period of $\mathbf{3}$ minutes. Mice in the last group received rimonabnat $(1 \mathrm{mg} / \mathrm{kg})$ prior to pregabalin. Data are mean \pm SEM and were analyzed using one-way ANOVA. Post-hoc analysis was performed to detect difference between individual groups at $\mathbf{P}<0.05$. * Significantly different from Dist. Water group, ${ }^{\mathrm{D}}$ Significantly different from diazepam group, ${ }^{\mathrm{P}}$ Significantly different from pregabalin $(50 \mathrm{mg} / \mathrm{kg})$ group.

with the CB1 antagonist diminished the time spent in open area but not the number of entries to the white box. It is known that the first one is more sensitive to change in anxiolytic activity. Our results in the plus maze test, provided more important results as the cannabinoid antagonist reduced the two measured parameters tested in the maze giving more reliable conclusion and supported the findings of the first test.

The results of Pande et al (2003) indicated that Pregabalin is effective safe and rapidly acting treatment in patients with GAD. During short treatment regimens, Pregabalin did not show withdrawal symptoms such as those reported with benzodiazepines.

Pregabalin was reported to produce ataxia and decrease locomotor function at doses that are 10-30fold greater than those active to control seizures. Results suggest that anticonvulsant action of Pregabalin is different in mechanism from the prototype antiepileptic medications and similar to gabapentin. Findings highlight that Pregabalin has many properties that make it superior in treating human partial seizures. Greater dosages $\left(\mathrm{ED}_{50}=31\right.$ $\mathrm{mg} / \mathrm{kg}$ ), Pregabalin was reported to prevent clonic seizures in mouse pentylenetetrazole model (Vartanian et al., 2006). 
The light/dark transition test has a limitation of the possibility of yielding false-positive results for a drug that increases general locomotor activity. In some experimental protocols, drugs that increase general motor function will further increase light/dark performance. Therefore, one preliminary screening for locomotor activity, such as an open field test, appears to be essential for elimination of falsepositive results and sufficient for this purpose. One other problem that appears when the white side of the box is not sufficiently aversive as this is the most critical feature and differentive between the two test sides. Different parameters and test procedures have been utilized and reported by different laboratories, so that the effects cannot be easily reproduced within and between laboratories and this may contribute to a number of false positive results. Various questions are raised about the validity of some pre-clinical results and suggest that more attention should be paid to the publication of nonsignificant effects.

Additional actions of gabapentin or Pregabalin that have been described in vitro and it is not confirmed to be of therapeutic relevance. These functions include increased distribution of GABA transporter protein from an intracellular location to plasma membrane of cultured neurons (Whitworth and Quick, 2001), an action not shared by Pregabalin. Additional experiments will be required to demonstrate the relevance of these effects in vivo.

In rat hippocampus in vivo, both Pregabalin and gabapentin caused electrophysiological changes different from those of a GABAA positive modulator, a GABA uptake blocker or a GABA degradation inhibitor (Stringer and Aribi, 2002; Stringer and Taylor, 2000). Therefore, neither Pregabalin nor gabapentin appears to be GABAmimetic or enhancers for the pharmacological action, suggesting that GABA effects do not account for their pharmacological activity.

The initial chemical synthesis that discovered Pregabalin was relying on altering inhibitory synaptic activity in brain by interacting with GABA synthetic enzymes in brain such as glutamic acid decarboxylase, which is the primary GABA synthetic enzyme. Although gabapentin and Pregabalin were reported to augment the activity of glutamic acid decarboxylase in vitro (Silverman et al., 1991), one subsequent study with rat brain showed that neither gabapentin nor Pregabalin altered concentration of GABA in brain tissues (Errante and Petroff, 2003), while the known GABA transaminase inhibitor, vigabatrin, increased brain GABA levels. In vitro, Pregabalin and gabapentin did not inhibit GABA transport like the known GABA uptake inhibitor, tiagabine (Su et al., 2005).

\section{Conclusion}

The current study provided some evidence that CB1 receptors-mediated response account for the anxiolytic-like effect of Pregabalin. Further studies are needed to support the present findings in other models of anxiety in rodents beside important confirmatory ligand binding assays.

\section{Conflict of interest}

The authors report no declaration of conflict of interest.

\section{Acknowledgements}

No acknowledgement. 


\section{References}

Arnold, L.M., 2010. The pathophysiology, diagnosis and treatment of fibromyalgia. Psychiatric Clinics of North America. 33(2), 375-408.

Barraco, R.A., 1991. Behavioral actions of adenosine and related substances. In: Phillis JW (ed) Adenosine and adenine nucleotides as regulators of cellular function. CRC Press, Boca Raton, Fl, pp 339-365.

Belliotti, T.R., Capiris, T., Ekhato, I.V., Kinsora, J.J., Field, M.J., Heffner, T.G., Meltzer, L.T., Schwarz, J.B., Taylor, C.P., Thorpe, A.J., 2005. Structure activity relationships of Pregabalin and analogues that target the a2-d protein. J. Med. Chem. 48, 22942307.

Belzung, C., Misslin, R., Vogel, E., Dodd, R.H., Chapouthier, G., 1987. Anxiogenic effects of methylh-carboline-carboxylate in a light/dark choice situation. Pharmacol. Biochem. Behav. 28, 29-33.

Carobrez, A.P., Bertoglio, L.J., 2005. Ethological and temporal analyses of anxiety-like behavior: the elevated plus-maze model 20 years on. Neurosci. Biobehav. Rev. 29(8), 1193-1205.

Eutamene, H., Coelho, A.M., Theodorou, V., Toulouse, M., Chovet, M., Doherty, A., Fioramonti, J., Bueno, L., 2000. Antinociceptive effect of Pregabalin in septic shock-induced rectal hypersensitivity in rats. J. Pharm. Exp. Ther. 295(1), 162-167.

Crawley, J.N., Goodwin, F.K., 1980. Preliminary report of a simple animal behaviour for the anxiolytic effects of benzodiazepines. Pharmacol. Biochem. Behav. 13, 167-170.

Compton, D.R., Dewey, W.L., Martin, B.R., 1990. Cannabis dependence and tolerance production. Adv. Alcohol Subst. Abuse. 9, 129-147.

De Vry, J., Benz, U., Schreiber, R., Traber, J., 1993. Shock-induced ultrasonic vocalization in young adults rats: a model for testing putative antianxiety drugs. Eur. J. Pharmacol. 249 (3), 331- 339.
Dworkin, R.H., O'Connor, A.B., Audette, J., Baron, R., Gourlay, G.K., Haanpää, M.L., Kent, J.L., Krane, E.J., LeBel, A.A., Levy, R.M., Mackey, S.C., 2010. Recommendations for the pharmacological management of neuropathic pain: an overview and literature update. Mayo Clin. Proc. 85 (3), S3-S14.

Errante, L.D., Petroff, O.A.C., 2003. Acute effects of gabapentin and Pregabalin on rat forebrain cellular GABA, glutamate, and glutamine concentrations. Seizure. 12, 300-306.

Etkin, A., 2009. Functional neuroanatomy of anxiety: a neural circuit perspective. In Behavioral neurobiology of anxiety and its treatment. Springer Berlin Heidelberg. pp. 251-277.

Faerber, L., Drechsler, S., Ladenburger, S., Gschaidmeier, H., Fischer, W., 2007. The neuronal 5$\mathrm{HT}_{3}$ receptor network after 20 years of researchEvolving concepts in management of pain and inflammation. Euro. J. Pharmacol. 560, 1-8.

Feltner, D.E., Crockatt, J.G., Dubovsky, S.J., Cohn, C.K., Shrivastava, R.K., Targum, S.D., Liu-Dumaw, M., Carter, C.M., Pande, A.C., 2003. A randomized, double-blind, placebo-controlled, fixed-dose, multicenter study of Pregabalin in patients with generalized anxiety disorder. J. Clin. Psychopharmacol . 23(3), 240-249.

Field M.J., Oles R.J., Singh L. Pregabalin may represent a novel class of anxiolytic agents with a broad spectrum of activity. British journal of pharmacology 2001; 132:1-4.

File, S.E., 1992. Usefulness of animal models with newer anxiolytics. Clin. Neuropharmacol. 15 (1), 525A-526A.

Frampton, J.E., Foster, R.H., 2006. Pregabalin: in the treatment of generalised anxiety disorder. CNS drugs. 20, 685-694.

Griebel, G., Lanfumey, L., Blanchard, D.C., Rettori, M.C., Guaardiola-Lemaitre, B., Hamon, M., Blanchard, R.J., 1996. Preclinical profile of the mixed 5-HT1A/5-HT2A receptor antagonist S21357. Pharmacol. Biochem. Behav. 54, 509- 516 
Guo, S., 2009. Using zebrafish to assess the impact of drugs on neural development and function. Expert Opin Drug Discov. 4(7), 715-726.

Hascoet, M., Bourin, M., 1998. A new approach to the light/dark procedure in mice. Pharmacol. Biochem. Behav. 60, 645-653.

Holmes, A. and Rodgers, R.J., 1998. Responses of Swiss-Webster mice to repeated plus-maze experience: further evidence for a qualitative shift in emotional state? Pharmacol. Biochem. Behav. 60(2), 473-488

Lauria-Horner, B.A., Pohl, R.B., 2003. Pregabalin: a new anxiolytic. Expert Opin. Investig. Drugs. 12(4), 663-72.

Lister, R.G., 1987. The use of a plus-maze to measure anxiety in the mouse. Psychopharmacology. 92(2), 180-185.

Lister, R.G., 1990. Ethologically-based models of anxiety disorders. Pharmacol. Ther. 46, 321- 340.

Manzanares, J., Julian, M.D., Carrascosa, A., 2006. Role of the cannabinoid system in pain control and therapeutic implications for the management of acute and chronic pain episodes. Curr. Neuropharmacol. 4, 239-257.

Mellar, P.D., Gavril, W.P., 2009. Opioid receptors and opioid pharmacodynamics. In: Mellar PD, Paul AG, Columba Q, Janet H, editors. Opioids in cancer pain. New York: Oxford University Press, 1-28.

Montgomery, S.A., Nil, R., Durr-Pal, N., Loft, H., Boulenger, J.P., 2005. A 24-week randomized, double-blind, placebo-controlled study of escitalopram for the prevention of generalized social anxiety disorder. J. Clin. Psychiatry. 66(10),12701278 .

Ohl, F., 2005. Animal models of anxiety. In Anxiety and anxiolytic drugs. Springer Berlin Heidelberg. pp. 35-69.

Pande, A.C., Crockatt, J.G., Feltner, D.E., Janney, C.A., Smith, W.T., Weisler, R., Londborg, P.D., Bielski, R.J., Zimbroff, D.L., Davidson, J.R., Liu-
Dumaw, M., 2003. Pregabalin in generalized anxiety disorder: a placebo-controlled trial. Am. J. Psychiatry. 160(3), 533-40.

Pande, A.C., Feltner, D.E., Jefferson, J.W., Davidson, J.R., Pollack, M., Stein M.B., 2004. Efficacy of the novel anxiolytic Pregabalin in social anxiety disorder: a placebo-controlled, multicenter study. J. Clin. Psychopharmacol. 24,141-149.

Pellow, S., Chopin, P., File, S.E., Briley, M., 1985. Validation of open/closed arm entries in an elevated plus-maze as a measure of anxiety in the rat. $\mathrm{J}$. Neurosci. Methods 14, 145-167.

Rickels, K., Pollack, M.H., Feltner, D.E., Lydiard, R.B., Zimbroff, D.L., Bielski, R.J., Tobias, K., Brock, J.D., Zornberg, G.L., Pande, A.C., 2005. Pregabalin for treatment of generalized anxiety disorder: a 4week, multicenter, double-blind, placebo-controlled trial of Pregabalin and alprazolam. Arch. Gen. Psychiatry. 62(9), 1022-1030.

Rodgers, R.J., 1997. Animal models of 'anxiety': where next? Behav. Pharmacol. 8, 477-496.

Sills, G.J., 2006. The mechanisms of action of gabapentin and Pregabalin. Curr. Opin. Pharmacol. 6(1), 108-113.

Silverman, R.B., Andruszkiewicz, R., Nanavati, S.M., Taylor, C.P. Vartanian, M.G., 1991. 3-Alkyl-4aminobutyric acids: the first class of anticonvulsant agents that activates L-glutamic acid decarboxylase. J. Med. Chem. 34, 2295-2298.

Stringer, J.L., Aribi, A.M., 2002. Modulation of the in vivo effects of gabapentin by vigabatrin and SKF89976A. Epilepsy Res. 52, 129-137.

Stringer, J.L., Taylor, C.P., 2000. The effects of gabapentin in the rat hippocampus are mimicked by two structural analogs, but not by nimodipine. Epilepsy Res. 41, 155-162.

Svizenska, I., Dubovy, P., Sulcova, A., 2008. Cannabinoid receptors 1 and $2\left(\mathrm{CB}_{1}\right.$ and $\left.\mathrm{CB}_{2}\right)$, their distribution, ligands and functional involvement in nervous system structures. Pharmacol. Biochem. Behav. 90, 501-511. 
Su, T.Z., Feng, M.R., Weber, M.L., 2005. Mediation of highly concentrative uptake of Pregabalin by Ltype amino acid transport in Chinese hamster ovary and Caco-2 cells. J. Pharmacol. Exp. Ther. 313,14061415.

Vartanian, M.G., Radulovic, L.L., Kinsora, J.J., Serpa, K.A., Vergnes, M., Bertram, E., Taylor, C.P., 2006. Activity profile of Pregabalin in rodent models of epilepsy and ataxia. Epilepsy Res. 68(3),189-205.

Vogel, J.R., Beer, B., Clody, D.E., 1971. A simple and reliable conflict procedure for testing antianxiety agents. Psychopharmacologia. 21(1),1-7.

Weiss, S.M., Wadsworth, G., Fletcher, A. and Dourish, C.T., 1998. Utility of ethological analysis to overcome locomotor confounds in elevated maze models of anxiety. Neurosci. Biobehav. Rev. 23(2), 265-271.
Whitworth, T.L., Quick, M.W., 2001. Upregulation of g-aminobutyric acid transporter expression: role of alkylated g-aminobutyric acid derivatives. Biochem. Soc. Trans. 29,736-741.

Woods, S.W., Seibyl, J.P., Goddard, A.W., Dey, H.M., Zoghbi, S.S., Germine, M., Baldwin, R.M., Smith, E.O., Charney, D.S., Heninger, G.R., Hoffer, P.B., 1992. Dynamic SPECT imaging after injection of the benzodiazepine receptor ligand [123 I] iomazenil in healthy human subjects. Psychiatry Research: Neuroimaging. 45(2), 67-77.

Zohar, J., Matar, M.A., Ifergane, G., Kaplan, Z., Cohen, H., 2008. Brief post-stressor treatment with Pregabalin in an animal model for PTSD: short-term anxiolytic effects without long-term anxiogenic effect. Eur. Neuropsychopharmacol. 18, 653-666. 